\title{
Correction to: Can digital transformation of the enterprise break the monopoly?
}

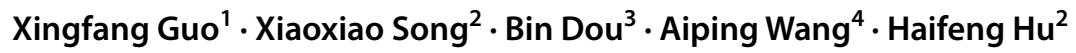

๑) Springer-Verlag London Ltd., part of Springer Nature 2022

\section{Correction to: Personal and Ubiquitous Computing https://doi.org/10.1007/s00779-022-01666-0}

In the original paper provided by authors, there is a spelling mistake in the author name. The name of the first author should be Xingfang Guo but not Xinfang Guo. I declare to correct this mistake on behalf of all authors.

The original article has been corrected.

Publisher's Note Springer Nature remains neutral with regard to jurisdictional claims in published maps and institutional affiliations.

The original article can be found online at https://doi.org/10.1007/ s00779-022-01666-0.

Aiping Wang

wangaiping@btbu.edu.cn

1 School of Economics, Henan University, Kaifeng 475004, China

2 Business School, Beijing Normal University, Beijing 100875, China

3 School of Social Science, Tsinghua University, Beijing 100084, China

4 School of Economics, Beijing Technology and Business University, No.11 Fucheng Road, Beijing, China 